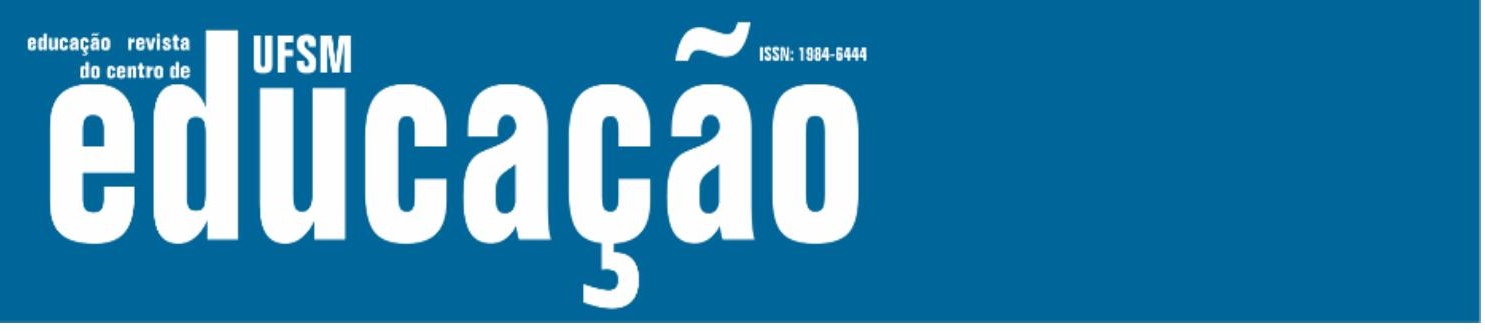

ISSN: 1984-6444 | http://dx.doi.org/10.5902/1984644438695

\title{
A pesquisa na formação do professor universitário: competências na produção e transmissão do conhecimento
}

Research in the training of university teachers: skills in the production and transmission of knowledge

Jenekésia Lins da Silva

Doutoranda na Universidade Federal de Alagoas, Maceió, Alagoas, Brasil.

jenekesialins@hotmail.com - http://orcid.org/0000-0003-0064-1206

Ana Paula Monteiro Rêgo

Professora assistente da Universidade Estadual de Alagoas, Maceió, Alagoas, Brasil. ana-monteirorego@bol.com.br - https://orcid.org/0000-0002-7505-2476

Luís Paulo Leopoldo Mercado

Professor doutor na Universidade Federal de Alagoas, Maceió, Alagoas, Brasil.

luispaulomercado@gmail.com - https://orcid.org/0000-0001-8491-6152

Recebido em 23 de junho de 2019

Aprovado em 14 de janeiro de 2021

Publicado em 10 de março de 2021

\section{RESUMO}

Este artigo traz a produção de pesquisa como uma das mais importantes atribuições do professor universitário. A formação universitária do profissional de Educação, como professor de graduação, não é considerada suficiente para o desenvolvimento da capacidade de produzir e tornar o grupo de professores em pesquisadores. As formações e pós-graduações possibilitam reflexões acerca da formação dos professores universitários e suas atribuições e enfatizam discussões sobre a pesquisa na universidade. Este é um artigo de reflexão teórica que teve como objetivo relatar os fundamentos teóricos de Perrenoud (2001), Tardif e Lahaye, (1991), Ramos (2010), Pimenta (2009), Gerhardt e Silveira (2009), Soares (2018), que nortearam as discussões ocorridas no Curso de Formação Continuada "Atuação e Competências do Professor Universitário" do Curso de Pós-graduação em Educação, na disciplina Metodologia do Ensino Superior com Tecnologias da Informação e Comunicação da Universidade Federal de Alagoas (UFAL) durante o primeiro semestre de 2018. Como forma de elucidar o percurso de uma formação que favoreça a habilidade de desenvolver pesquisa na universidade, apresentamos a construção de um Curso de Formação para professores universitários como pesquisadores e orientadores de pesquisas. Os resultados deste estudo podem ser utilizados como percurso de 


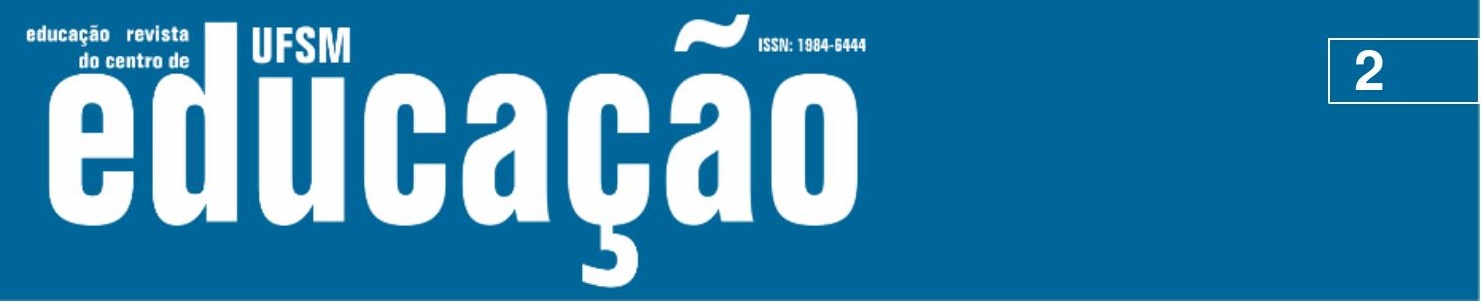

ISSN: 1984-6444 | http://dx.doi.org/10.5902/1984644438695

formação de professores com ênfase na pesquisa. A pesquisa na formação docente fomenta inovação na prática pedagógica no intuito de fornecer subsídios para a produção do conhecimento, o qual induz progressão positiva na prática pedagógica e promove uma formação reflexiva sob a óptica da transmissão do conhecimento.

Palavras-chave: Formação docente, Competências, Pesquisa, Ensino superior.

\section{ABSTRACT}

This articles brings research production as one of the most important responsibilities of a university professor. Academic instruction of the education profession, as a graduate professor, is not considered sufficient to develop his ability to produce and make a group of teachers into researchers. Graduate and postgraduate degrees allow for reflections about university professors training, their duties and they emphasize discussions about university research. This is an article of theoretical thoughts that aimed to report theoretical foundations from Perrenoud (2001), Tardif e Lahaye (1991), Ramos (2010), Pimenta (2009), Gerhardt and Silveira (2009), Soares (2018), which guided discussions held at the "Continuing Education and Skills of the University Professor" class of the postgraduate course in Education, in the Methodology of Higher Education with ICT class of the Federal University of Alagoas during the first semester of 2018. As a way to elucidate the process of a training that facilitates the ability to develop research in the university, we propose to create a training course for university professors as researchers and research advisers. Study results can be used as a guideline for a training course for professors with an emphasis on research. Research in teacher education promotes innovation in pedagogical practices in order to provide subsidies to produce knowledge, which induces positive progression in pedagogical practices and promotes reflective formation from a knowledge transmission point of view.

Keywords: teacher training, skills, research, higher education.

\section{Introdução}

Na Universidade, a pesquisa é um dos temas mais discutidos entre professores e estudantes, sendo de responsabilidade do professor universitário favorecer sua efetividade. A importância da pesquisa fomenta a perspectiva de formar um professor pesquisador no contexto universitário e concernente mudança de prática docente no exercício de sua profissão.

A docência universitária no âmbito da pesquisa nos remete a um compromisso social, o qual se refere a uma responsabilidade com as investigações e formação de 


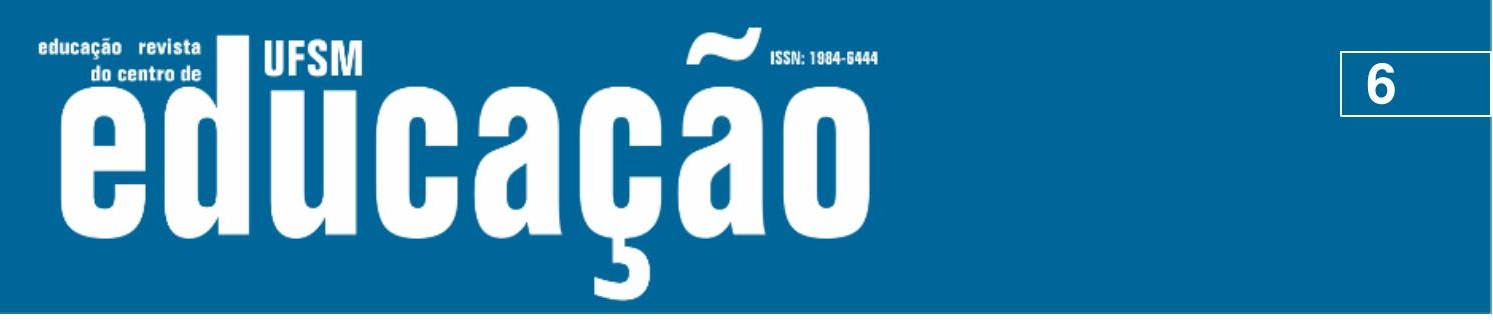

ISSN: 1984-6444 | http://dx.doi.org/10.5902/1984644438695

possibilitem competências de forma coerente e não acumulação de unidades para formação;

7. Avaliação formativa baseada na análise do trabalho - fundamentada na percepção de uma avaliação formativa, na qual a aprendizagem e a realimentação sejam importantes e que possibilitem uma desenvoltura em suas próprias competências em matéria de observação e de análise do trabalho e das situações.

8. Tempos e dispositivos de interação e de mobilização das aquisições - a formação do professor deverá ser pautada em planos de formação, tempos e dispositivos que viabilizassem, especificamente, a integração e mobilização das aquisições;

9. Parceria negociada com os profissionais - pretende-se construir uma forte transposição didática próxima à prática e criar uma forte parceria com instituições de formação de professores, levando em consideração o sistema educacional e estabelecimentos escolares para acolher os estagiários;

10. Divisão dos saberes favorável à mobilização no trabalho - a formação inicial dos professores deve contrapor ao curso de formação, no qual deve oferecer subsídios aos estudantes, unidades de formação centradas em enfoques coerentes e relativamente estáveis.

Tardif e Lahaye (1991) destacam que o professor sempre está em fase de mudança, devido às novas formas da utilização do saber, no qual, potencializa mudança de práticas e competências para o fundamento da formação e atuação do professor no contexto escolar. O saber docente é definido como um saber plural, que constitui uma visão argumentativa e social, que viabiliza uma relação interativa entre o conhecimento e a sociedade.

O professor precisa de uma postura frente às novas atividades do aprender profissional que o habilite como pesquisador. Para atender a essa exigência é necessário considerar os desafios em saber lidar com o conhecimento que, na sociedade contemporânea, é considerado como transitório. Nesse contexto, ser professor universitário demanda: capacidade de autoaprendizagem; habilidade para tomar decisões; competência para avaliar domínios de escritas e aspectos cognitivos 


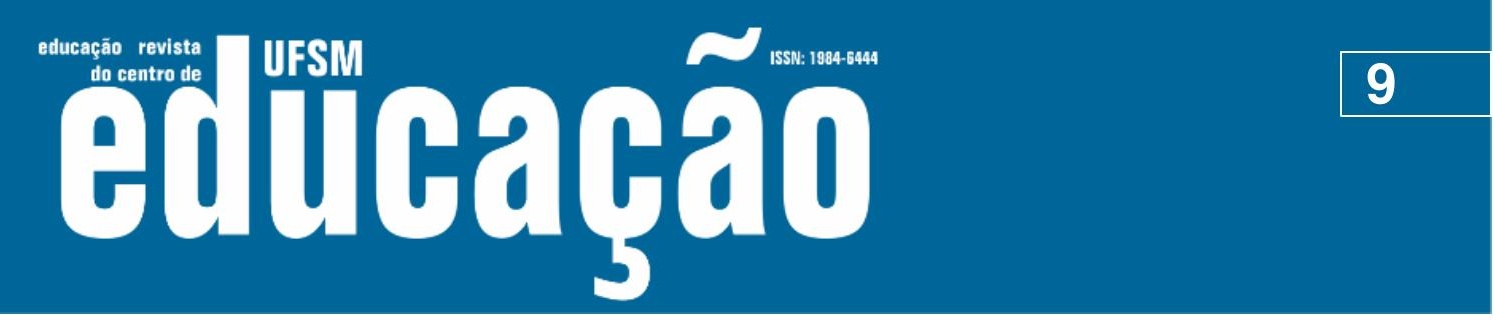

ISSN: 1984-6444 | http://dx.doi.org/10.5902/1984644438695

possibilita ao professor universitário construir seu próprio conhecimento de maneira pessoal e coletiva, tendo em vista, que o adquirido favorece o coletivo de forma que a capacidade do professor pesquisador é fundamental em captar e compreender a realidade de forma eficaz e positiva. A construção da identidade da docência, no ensino superior, corresponde a ser pesquisador,

Ludke e Cruz (2005, p. 12) defendem que "a pesquisa continua a ser a moeda mais valiosa na contabilidade da carreira do professor universitário", levando em consideração situações problemáticas que potencializem o envolvimento do professor com a investigação para solucionar problemas satisfatórios. Para tal, é necessário que o professor reveja sua prática e conduza sua autoavaliação a fim de compreender situações-problemas existentes no dia a dia no contexto escolar. As autoras ainda afirmam: "a pesquisa efetuada na universidade beneficia-se dos recursos e da preparação dos futuros pesquisadores, que exercem essa atividade como própria de seus status e de suas atribuições" (LUDKE E CRUZ 2005, P. 12). Contudo, a falta da pesquisa na universidade evidencia profissionais a reconhecerem a ausência de produtivismo em sua prática ao levar à sociedade um profissional habilitado que perceba os problemas que afligem a profissão docente no nível superior.

A prática social do professor remete-se às concepções de ensino e a prática social do professor pesquisador emerge em contextos históricos, pois o aproxima de situações-problemas postos pela sociedade que potencializam a exigência do domínio de ensino. Há poucos professores com experiência sistêmica de pesquisa, apesar de considerarmos que existem formações continuadas, em nível de pós-graduação, que objetivam a prática sistemática da pesquisa, favorecendo que o professor possa avançar de acordo com suas perspectivas pessoais, atendendo ou não, às demandas institucionais de exigências do mercado de trabalho (PIMENTA, 2009).

\section{Contribuição da Pesquisa e Ensino no Universo Acadêmico}

O homem é um pesquisador por natureza. A história do desenvolvimento humano é marcada pela relação do homem com os objetos e pela busca de respostas sobre estes objetos, bem como, pelas possibilidades de transformação dele, mediante 


\section{Ism outibahá}

ISSN: 1984-6444 | http://dx.doi.org/10.5902/1984644438695

pesquisa como uma das competências e habilidades exigidas no Campus Universitário.

No texto de Pimenta (2009) aparece o reflexo da identidade do ser professor e a sistematização de elementos constituintes para um curso de formação inicial de professor, a partir da construção da identidade da docência na universidade. Ao mesmo tempo, ele aborda aspectos relacionados em à "Docência na universidade: ensino e pesquisa" em que destaca a importância da construção da identidade profissional, refletindo o ensino e a pesquisa na prática docente e nos componentes que são configurados na atividade de pesquisar e ensinar. Reforça, também, a ideia de que, para sustentar a pesquisa em sala de aula, fazem-se necessários posicionamento de flexibilidade e coragem e o confronto entre ações pessoais e profissionais. Dessa forma, a ação profissional possui características relevantes que levam o estudante a caminhos que tem a ver com o reflexo da prática da pesquisa profissional visando o repassar do conhecimento a estudantes que ocupam a sala de aula na universidade.

Pimenta (2009) destaca dois benefícios aos professores do ensino superior em formação, dos quais, os mais significativos são:

\section{Benefícios aos pós-graduandos como futuros docentes imediatos ao} sistema de ensino na graduação -esse benefício revela o compromisso do futuro professor e sua prática na universidade, que possibilita habilidades, competências e reflexões sobre diferentes modos de execução e prática no contexto universitário.

Benefícios aos programas de pós-graduação e às atividades com os estudantes e disciplinas de graduação -a ampliação do conhecimento possibilita aos professores oportunidades para repensar suas experiências em sala de aula.

O desenvolvimento da identidade docente, para Pimenta (2009, p. 50) não é algo "imutável, mas é um processo de crescimento profissional", sendo esta identidade do professor, meramente, constante no que se refere à formação profissional, a partir dos desenvolvimentos das culturas tradicionais e momentos históricos que adquirem nas legalidades impostas pelas sociedades e pelo poder legal que permanecem com práticas altamente burocráticas. 


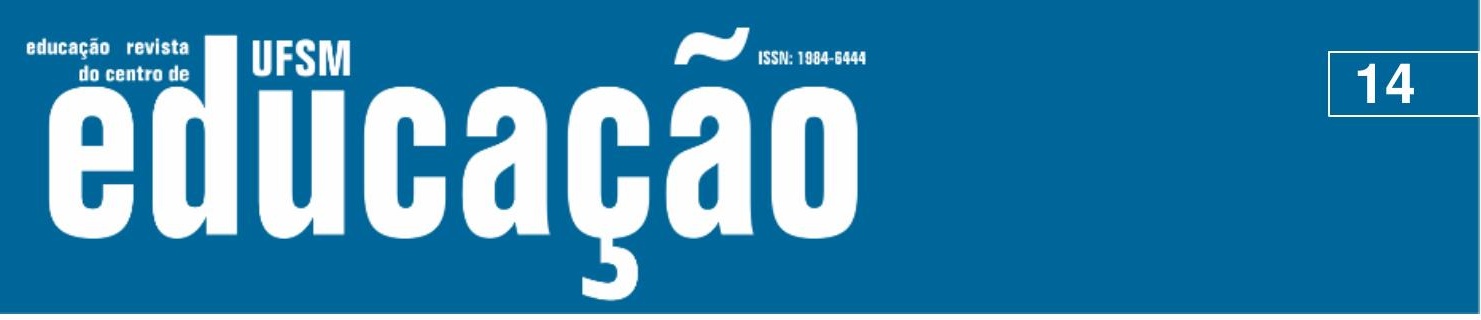

ISSN: 1984-6444 | http://dx.doi.org/10.5902/1984644438695

Masetto (1998) destaca o surgimento do ensino superior no Brasil e nos leva a refletir a formação inicial dos profissionais sob a óptica da totalidade, apresentando as competências que são exigidas ao professor e listando os desafios impostos pela atividade docente na universidade. Expõem questionamentos acerca do professor de ensino superior quando este é identificado como o professor experiente e avaliado, e como aquele que tem o dom de ensinar. Reitera que o professor universitário é identificado, muitas vezes, como àquele profissional que consegue apresentar bom desempenho quando ministra aulas expositivas ou profere palestras sobre um conhecimento específico e, ainda, consegue provar na prática como aplica seu saber especializado.

A preocupação das universidades com a formação docente é contemporânea. As Instituições de Ensino Superior - IES, no século XXI, conscientizaram-se acerca da necessidade de formações que garantam o desenvolvimento de competências específicas que a prática docente exige. A ideia de que basta ter diplomas de licenciatura ou bacharel, mestre ou doutor para ser um bom professor é considerada obsoleta e/ou ingênua, bem como há, no panorama atual das universidades, uma preocupação com a formação do estudante em cursos superiores, primando-se por uma organização curricular que imponha uma transmissão de conhecimentos, possibilite experiências profissionais, favoreça a integração do estudante e aperfeiçoe a formação dos futuros profissionais (MASETTO, 1998).

Os cursos do ensino superior sofrem algumas represálias no que se refere à formação de profissionais, seja pelo histórico inicial, aqui já comentado, ou pelo difícil papel de formar diferentes profissionais, nas mais diversas áreas do conhecimento, para atender a amplas demandas sociais. Este panorama dinâmico exige adequações de todo o sistema de ensino superior atribuições e competências específicas do professor universitário.

Masetto (1998) destaca as competências que a docência universitária exige de seus candidatos a professor do ensino superior:

\section{A docência em nível de ensino superior exige do profissional competência} em uma determinada área de conhecimento - essa competência exige domínios básicos de conhecimentos em uma determinada área, bem como a experiência do 


\section{Fism elturará

ISSN: 1984-6444 | http://dx.doi.org/10.5902/1984644438695

Partindo dos conceitos até aqui apresentados, foi planejado o Curso "online": Atuação e Competências do Professor Universitário. O Curso tem caráter acadêmico e pode ser utilizado como modelo de formação continuada. O módulo abaixo enfatiza a pesquisa como habilidade do professor universitário. Este curso foi planejado para ser desenvolvido com carga horária de 40 horas e de forma, exclusivamente, "online".

Figura 1 - Abertura do módulo

\section{Atuação Docente na Pesquisa}

Caros Alunos

Sejam bem-vindos ao nosso curso a distância sobre as Competências do Professor Universitário. Vocês transcorrerão por diversos contextos de atuação do Professor na universidade e neste modulo encontrarão peculiaridades relacionadas à atuação do docente na pesquisa.

Dentro do que preparamos para vocês estarão informações acerca da importância em direcionar estudos científicos que favorecem maior mobilidade e conhecimento no campo da pesquisa, bem como aporte teórico com base empírica para dar robustez ao conteúdo.

Acompanhem a sistemática de avaliação, carga horária e outras informações importantes para realização das atividades. Além disso, vocês poderão acompanhar as datas e prazos para que possam aproveitar o máximo os conteúdos abordados e dinamizados em atividades.

Contamos com sua dedicação no cumprimento de todas as atividades para o melhor aproveitamento.

Desejamos um ótimo módulo.

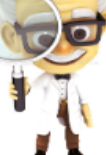

-Veja a ementa e objetivos do módulo; - Leia o texto base que explana sobre o docente e a pesquisa na universidade; - Conheça a experiência de uma professora pesquisadora descrevendo seu percurso na docência e na pesquisa; - Participe do fórum interativo e realize a atividade proposta; - Leia os textos complementares

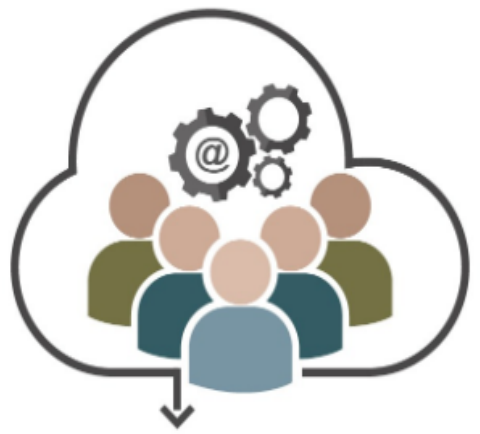

Ementa e Objetivo

Texto sobre O Docente e a Pesquisa na Universidade

U⿴囗十 Modulo I: Contradições na pesquisa e pós-graduação no Brasil

Módulo Il: Vídeo sobre a Importância do Docente na Prática da Pesquisa

Resumo Crítico

Fonte: Dados dos autores (2019). 


\section{Tusm Aitlathat

ISSN: 1984-6444 | http://dx.doi.org/10.5902/1984644438695

O curso "Atuação e Competências do Professor Universitário" pode proporcionar ao professor universitário uma orientação sobre a pesquisa na universidade, uma vez que sua atuação na Academia favorece a pesquisa e o seu desempenho como professor pesquisador e orientador.

\section{Desenvolvimento de habilidades para a pesquisa na universidade: proposta de um curso de formação "online"}

Nessa seção descreveremos o planejamento do curso de formação de professores com ênfase no desenvolvimento das habilidades para o desenvolvimento e o acompanhamento de pesquisas na universidade. Esse Curso foi realizado em formato online, tendo como recurso o ambiente virtual de aprendizagem (AVA) Moodle.

A ementa do curso envolve: pesquisa acadêmica como campo de atuação e competência do professor universitário; método científico e questões éticas na pesquisa; métodos de pesquisa e possibilidades de registro das investigações científicas e das múltiplas possibilidades do desenvolvimento de atividades acadêmicas envolvendo pesquisa no dia a dia do professor universitário.

O curso tem por objetivo favorecer o desempenho do professor universitário como pesquisador e orientador de pesquisas; explanar os fundamentos teóricos que norteiam a atuação do professor como pesquisador na universidade; apresentar o panorama nacional da pesquisa na universidade e apontar as formas de inserção do professor neste cenário.

Os conteúdos a serem trabalhados são: o cenário da pesquisa nas graduações e pós-graduação no Brasil; o professor e a pesquisa na universidade; os desafios de ser professor pesquisador.

A metodologia utilizada envolve as seguintes práticas didáticas pedagógicas:

a) discussão da relação da docência no contexto da pesquisa e sua influência no processo de ensino e aprendizagem, com base na leitura do texto: contradições na pesquisa e pós-graduação no Brasil (SOARES, 2018); 


\section{Fism Autlatato}

ISSN: 1984-6444 | http://dx.doi.org/10.5902/1984644438695

b) construção de mapa conceitual e um texto resumido no qual deve ser explanado o contato de cada estudante com a pesquisa na universidade;

c) disponibilidade de um vídeo da experiência de uma professora que apresenta sua vivência com pesquisa numa universidade. $O$ vídeo foi realizado mediante roteiro prévio de perguntas que tinham como proposta esboçar a importância da pesquisa, apresentar as dificuldades em realizá-las, o fazer pesquisa no dia a dia da universidade e o trabalho com os estudantes na produção da pesquisa. Foi sugerida uma síntese descritiva dos pontos mais importantes expostos na entrevista disponibilizada.

d) realização do fórum de discussão no AVA Moodle sobre metodologias de pesquisa e as possibilidades de aplicação de cada uma, destacando as etapas de uma pesquisa;

e) elaboração de um plano de intenção de pesquisa orientado pelo moderador no AVA Moodle.

O curso é encerrado com mais um fórum com apresentação das orientações gerais acerca do projeto de pesquisa, considerando as possibilidades de ampliação dos planos de intenção. $\mathrm{Na}$ avaliação do Curso serão consideradas a observação e participação das atividades (fórum e tarefas) e apresentação do plano de intenção de pesquisa ou projeto de pesquisa.

A avaliação é contínua no desenvolvimento do exercício da profissão, tendo seu caráter diagnóstico e formativo, na disseminação de conhecimentos para uma melhoria da prática pedagógica, considerando a participação individual e coletiva dos estudantes nas atividades propostas.

\section{Considerações finais}

Pelos estudos apresentados, percebemos que a pesquisa é de fundamental importância para a formação docente. Analisamos literaturas e verificamos que o processo de pesquisa exige uma preparação, por parte do professor, para a formação inicial de um profissional e para própria prática pedagógica. Contudo, este artigo 


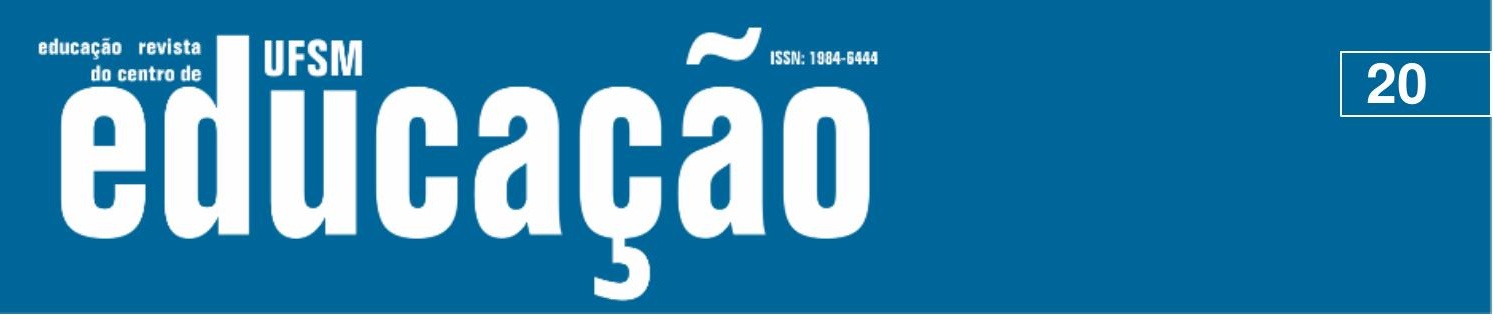

ISSN: 1984-6444 | http://dx.doi.org/10.5902/1984644438695

LUDKE, Menga; CRUZ, Giseli Barreto da. Aproximando universidade e escola de educação básica pela pesquisa. Cadernos de Pesquisa. v. 35, n.125, São Paulo maio/ago. 2005.

MASETTO, Marcos T. Docência na universidade. Campinas: Papirus, 1998.

NERVO, Alessandra Cristiane dos Santos; FERREIRA, Fábio Lustosa. A importância da pesquisa como principio educativo para a formação científica de educando no ensino superior. Revista Educação em Foco, n. 7, 2015, p. 31-40.

SHIGUNOV NETO, Alexandre; MACIEL, Lizete Shizue Bomura. A importância da pesquisa para a prática pedagógica dos professores que atuam na educação superior brasileira: algumas discussões iniciais. Revista Brasileira de Docência, Ensino e Pesquisa em Administração, v. 1 n.1, p. 04-23, maio. 2009.

PERRENOUD, Philippe. Dez novas competências para uma nova profissão. Pátio Revista Pedagógica. n. 17, maio/julho, 2001, p. 8-12.

PERRENOUD, Philippe. A formação dos professores no século XXI. In: PERRENOUD, Philippe; THURLLER, Monica Gather (Orgs.). As competências para ensinar no século XXI: a formação dos professores e o desafio da avaliação. Porto Alegre: Artmed, 2002․․ p. 11-33.

PIMENTA, Selma, Garrido. A profissão professor universitário: processo de construção da identidade docente. In: CUNHA, Maria Isabel et al. (org). Docência universitária: profissionalização e práticas educativas. Feira de Santana: UEFS Editora, 2009, p. 33-55.

RAMOS, Katia Maria da Cruz. Reconfigurar a profissionalidade docente universitária: um olhar sobre ações de atualização pedagógico-didática. Porto: Universidade do Porto, 2010.

SOARES, Paulo César. Contradições na pesquisa e pós-graduação no Brasil. Estudos Avançados, n 32. 2018, p. 289-313

TARDIF, Maurice; LESSARD, Claude; LAHAYE, Louise. Os professores face ao saber: esboço de uma problemática do saber docente. Anais: Seminário de Pesquisa Sobre o Saber Docente na Faculdade Federal do Ceará, Fortaleza, 1991.

VASCONCELLOS, Maura Maria Morita; OLIVEIRA, Cláudia Chueire de. Docência na universidade: compromisso profissional e qualidade de ensino na graduação. Santa Maria, Educação, v. 36, n.2, p. 219-234, maio/ago. 2011.

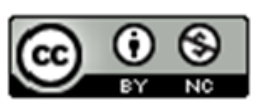

This work is licensed under a Creative Commons Attribution-NonCommercial 4.0 International (CC BY-NC 4.0) 